\title{
Comparative Assessment of the National Pharmacovigilance Systems in East Africa: Ethiopia, Kenya, Rwanda and Tanzania
}

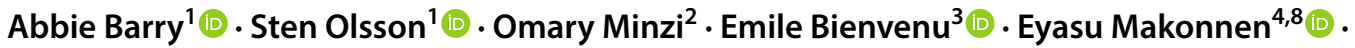 \\ Appolinary Kamuhabwa ${ }^{2} \cdot$ Margaret Oluka $^{5}$ - Anastasia Guantai ${ }^{5}$. Ulf Bergman ${ }^{1} \cdot$ Eugène van Puijenbroek $^{6}(1)$. \\ Parthasarathi Gurumurthy ${ }^{7}$ (i) Eleni Aklillu ${ }^{1}$ (i)
}

Published online: 9 January 2020

(c) The Author(s) 2020

\begin{abstract}
Introduction The increased access to medicinal products in Africa is not well-matched with the pharmacovigilance capacity to monitor drug safety. The objective of this study was to assess the functionality and identify the strengths and limitations of the national pharmacovigilance systems in Ethiopia, Kenya, Rwanda, and Tanzania, and compare these systems.

Methods Legal and statutory documents governing the pharmacovigilance systems of each participating country were examined by assessors prior to on-site review. The staff of the pharmacovigilance unit of the National Medicines Regulatory Authorities (NMRAs) were interviewed using the East African Community Harmonized Pharmacovigilance Indicators tool, supplemented with indicators from the World Health Organization (WHO) Global Benchmarking Tool. Responses were recorded, and data were analyzed.

Results The pharmacovigilance systems were supported by law and regulations in line with international standards. Standard operating procedures for receiving, processing, and communicating suspected adverse event reports were in place, but reporting of suspected medicine-related harm from stakeholders was inadequate in all countries. The number of Individual Case Safety Reports (ICSRs) received by NMRAs in Kenya, Ethiopia, and Tanzania (mainland) were 35.0, 6.7, and 4.1 per million inhabitants, respectively, in the last calendar year. At the time of assessment, Rwanda did not have an operational system. Overall, $\leq 1 \%$ of the total number of health facilities per country submitted ICSRs. Only Kenya and Tanzania had a designated budget for pharmacovigilance activities and an electronic ICSR reporting system. The national pharmacovigilance systems in all four countries did not have access to data on drug utilization.

Conclusions The national pharmacovigilance systems in the four East African countries have policy and legal frameworks defined by law and regulation to conduct pharmacovigilance activities. However, the four national pharmacovigilance systems are at different levels of capacity and performance with respect to conducting pharmacovigilance activities. Targeted interventions are needed to strengthen the pharmacovigilance systems to enable evidence-based decision making for patient safety.
\end{abstract}

\section{Introduction}

National Medicines Regulatory Authorities (NMRAs) have a mandate to protect the health and wellbeing of the people of their countries. The primary objective of NMRAs is to safeguard the public from unsafe medicinal products [1]. NMRAs are also responsible for promoting the rational use of medicinal products and minimizing the availability of Substandard and Falsified (SF) medicinal products [2]. Access to medicines in Africa is improving, mainly due to

Abbie Barry

abbie.barry@ki.se

Extended author information available on the last page of the article global health initiatives and the commitment of national governments to address diseases of public health concern like human immunodeficiency virus (HIV), neglected tropical diseases (NTDs), and tuberculosis amongst others [3, 4]. However, the increase in access to medicinal products is not well-matched with the capacities of the NMRAs to monitor the safety of medicines [3-5]. According to the World Health Organization (WHO), there are 54 NMRAs in Africa of varying capacities, but most of them are not capable of performing the key functions expected of NMRAs [2, 6]. In 2005, WHO reported that only $7 \%$ of the NMRAs in Sub-Saharan Africa (SSA) had a moderately developed medicine regulatory capacity [7], while $87 \%$ did not have a functional pharmacovigilance system [4]. In 2011, out of the 46 countries 


\section{Key Points}

This study compared the existence and performance of key pharmacovigilance structures, processes, and outputs/outcomes in the four PROFORMA project-participating East African countries (Ethiopia, Kenya, Rwanda, and Tanzania) to identify the current strengths and gaps.

The National Medicines Regulatory Authorities in these countries are at different capacity and performance levels with respect to conducting various pharmacovigilance activities.

This comparative assessment highlights the current gaps in the national pharmacovigilance systems in Ethiopia, Kenya, Rwanda, and Tanzania for future targeted interventions by relevant stakeholders.

in SSA, 25 (54\%) had minimal or no pharmacovigilance capacity and only four out of the 46 countries $(9 \%$ ) had pharmacovigilance systems with the capacity to detect, evaluate, and prevent safety issues, indicating the limited capacities of these countries to monitor medicines safety [8].

Globally, adverse drug reactions (ADRs), poor product quality, and inappropriate use such as medication errors contribute significantly to morbidity and mortality and have a huge impact on the healthcare system [9]. Few studies have investigated ADR-induced morbidity and mortality and their economic burden in Africa. According to a recent systematic review, ADRs are an important cause of morbidity in Africa, with the median prevalence of suspected ADRs on hospital admission and hospital admission as a result of an ADR being $8.4 \%$ and $2.8 \%$, respectively [10]. The systematic review also reported that about $44 \%$ of the ADRs were preventable. Poor product quality is also an issue in Africa, but due to limited studies, the magnitude of this problem has not been adequately quantified. In 2013 , poor-quality anti-malarial products alone were estimated to contribute to 91,577-154,736 deaths among children in 39 SSA countries [11].

Ethiopia, Kenya, Rwanda, and Tanzania are all members of the WHO Programme for International Drug Monitoring (PIDM) operated by the Uppsala Monitoring Centre (UMC) in Sweden. Tanzania (Tanzania Food and Drugs Authority [TFDA], now known as Tanzania Medicines and Medical Devices Authority [TMDA]) was the first to join the program in 1993, followed by Ethiopia (Ethiopian Food, Medicine and Health Care Administration and Control Authority [FMHACA], now known as Ethiopian Food and Drugs Authority [EFDA]) in 2008. Kenya (Pharmacy and Poisons Board [PPB]) and Rwanda (Ministry of Health) joined in 2010 and 2013, respectively [12]. The requirements to join the WHO PIDM include submission of 20 reports in the internationally accepted E2B format to UMC and a formal letter from the ministry of health requesting to join the program [13]. Even though all the four countries are members of the WHO PIDM, they have different capacities. An assessment conducted in 2011 showed that Ethiopia, Kenya, and Rwanda were in group 2, which means that they had policy and legal frameworks for pharmacovigilance and organizational structures including an institution with a clear mandate for pharmacovigilance, guidelines and standard operating procedures (SOPs), a reporting form, and a safety advisory committee [8]. Tanzania was the only country out of the four that was in group 3, which included countries with capacity to collect and evaluate safety data on the basis of legal and organizational structures [8].

There is a need to carry out clinical trials in SSA because of the existing vast genetic diversity in the population. Over the last 10 years, the number of clinical trials conducted in Africa has increased [14]. In 2016, a total of 345, 243, 87, and 59 clinical trials were conducted in Kenya, Tanzania, Ethiopia, and Rwanda, respectively [14]. The increasing number of clinical trials is another reason why well-functioning NMRAs with robust pharmacovigilance systems in line with international norms and best practices are vital to protect the safety and rights of the participants [15]. Mass immunization programs are deployed throughout the African continent, but the capacity of NMRAs to monitor vaccine safety is limited. It is the responsibility of NMRAs to ensure the quality, safety, and effectiveness of vaccines and other pharmaceutical products [16].

Overall, the large-scale, targeted mass immunization and drug administration for prevention and control of NTDs, the increasing number of clinical trials, and increased access to medicines in Africa highlights the need to strengthen the capacity of NMRAs to protect the public from unsafe and poor-quality medicines. This assessment has served as a baseline for the PROFORMA project [17], which focuses on strengthening the national pharmacovigilance infrastructure and post-marketing surveillance system in Ethiopia, Kenya, Rwanda, and Tanzania. The aim of this study was, therefore, to conduct a comparative assessment of the current national pharmacovigilance system at the respective NMRAs in Ethiopia, Kenya, Rwanda, and Tanzania for future targeted capacity-building interventions to be carried out by the PROFORMA project.

\section{Methodology}

\subsection{Study Design and Assessment Tool}

This was a cross-sectional descriptive study to compare the current pharmacovigilance systems at the NMRAs in the four East African countries, namely, Ethiopia, Kenya, Rwanda, and Tanzania. 
The East African Community (EAC) Harmonized Pharmacovigilance Indicators tool was used in this assessment. This tool was derived from the WHO pharmacovigilance indicators and the Indicator-Based Pharmacovigilance Assessment Tool (IPAT) [18, 19]. The indicators are designed to assess the existence and performance of key pharmacovigilance structures, processes, and outputs/outcomes, thereby identifying the strengths and limitations. The tool for assessment of the NMRAs contained 58 indicators that address five pharmacovigilance components as outcome measures: (1) policy, law, and regulation; (2) systems, structures, and stakeholder coordination; (3) signal generation and data management; (4) risk assessment and evaluation; and (5) risk management and communication. The tool was further supplemented with a few additional indicators from the WHO Global Benchmarking Tool (GBT): VL01.03guidelines ensure that distributors, importers, exporters, healthcare institutions, consumers, and other stakeholders are encouraged to report ADRs and adverse events (AEs) to the MAH and/or National Regulatory Authority (NRA); VL01.04-legal provisions and regulations allow NRA to require manufacturers and/or MAHs to conduct specific studies on safety and effectiveness under specific conditions; and VL01.05-legal provisions, regulations, and guidelines require manufacturers and/or MAHs to designate an individual person to be in charge of the vigilance system [20].

\subsection{Review of Requested Documentation}

Before visiting the participating countries, key individuals with the overall responsibility and knowledge of the respective national pharmacovigilance system in each country were identified. They were informed about the assessment and asked to share the legal and statutory documents and other relevant information with the external assessment team 2 weeks before the assessment visit. The documents requested and shared included:

- Extracts of national legislation describing responsibilities of relevance for the function of the national pharmacovigilance system

- Pharmacovigilance regulations and guidelines promulgated by the Ministry of Health or the national regulatory authority determining roles and responsibilities of different stakeholders contributing to the pharmacovigilance system

- SOPs describing routine processes to be followed in the management and routine operation of the pharmacovigilance system

- Terms of reference for external advisers, e.g., members of adverse reaction advisory committees
- Agreements or contracts signed with other authorities or organizations of relevance to the function of the national pharmacovigilance system.

\subsection{Data Collection Assessment}

The assessment and data collection in the four countries were conducted from July to December 2018. The assessment team consisted of three individuals, and the respondents were between two and four NMRA staff members working in the pharmacovigilance unit. The adopted EAC Harmonized Pharmacovigilance Indicators tool was used during the interviews. Follow-up questions were asked as required until assessors had gained enough understanding of the availability and functionality of the relevant structure, process, systems, or outcomes/outputs. The responses were recorded on a template developed for data collection and were sent to the respondents for verification. The respondents were staff of the respective NMRAs, mainly pharmacists, except two; one was a medical doctor (Tanzania) and the other was a public health professional (Ethiopia).

\subsection{Comparative Analysis of Results from Individual Country Assessments}

The indicator tool was used as a guide for structured interviews. The data from the individual country assessment were collected and entered into a template developed for the purpose of the study based on the five pharmacovigilance components of the assessment tool. Tables and bar charts were used to compare the performance of indicators within the same component.

\subsection{Ethical Considerations}

This study assessed the national pharmacovigilance systems at the NMRAs in Ethiopia, Kenya, Rwanda, and Tanzania to identify the presence or absence of key pharmacovigilance performance indicators. The four NMRAs were part of the PROFORMA project and agreed to the assessment of their respective pharmacovigilance systems to identify their gaps for future targeted interventions. No personal data were collected, and the informants did not disclose any personal data. Therefore, ethical approval was not required.

\section{Results}

\subsection{Governance, Policy, Law, and Regulation}

The national pharmacovigilance programs of Ethiopia, Kenya, Rwanda, and Tanzania were well supported by legal instruments such as acts, regulations, and policies (Table 1). 
These legal documents defined the role of the NMRAs and their mandate to monitor the quality, safety, and efficacy of medicinal products.

Regulations to enforce the pharmaceutical industries' responsibilities to perform post-marketing safety surveillance (PMS) were available. It was mandatory for Marketing Authorization Holders (MAHs) to conduct PMS and report Individual Case Safety Reports (ICSRs) or medicine safety issues in Ethiopia, Rwanda, and Tanzania (Table 2). In Kenya, there was no legal provision that required MAHs to conduct post-marketing safety activities and report ADRs or medicine safety issues. However, these responsibilities were written in the pharmacovigilance guidelines. In Ethiopia and Tanzania, MAHs were required to regularly submit Periodic Safety Update Reports (PSURs) or Periodic Benefit-Risk Evaluation Reports (PBRERs), and the NMRAs had the mandate to require MAHs to submit pharmacovigilance plans, risk management plans, and/or risk minimization/mitigation plans. In Ethiopia, MAHs are expected to submit PSURs to the authority every 6 months during the first 2 years after marketing authorization and, after that, annually for 3 years.

The 2018 pharmacovigilance regulations and guidelines in Tanzania require manufacturers/MAHs to have a Qualified Person responsible for Pharmacovigilance (QPPV). The new pharmacovigilance guidelines in Kenya (recently approved) require MAHs to keep a pharmacovigilance master file and to employ a QPPV to be responsible for all product safety issues. Rwanda and Ethiopia were considering including these requirements in their new guidelines as stipulated in the draft EAC pharmacovigilance guidelines.

\subsection{Systems, Structures, and Stakeholder Coordination}

In Kenya and Rwanda, the national pharmacovigilance center was a unit of its own hosted by the PPB and Rwanda
Food and Drugs Authority (Rwanda FDA), respectively. In both Ethiopia and Tanzania, the national pharmacovigilance program was managed under the Clinical Trials Control and Pharmacovigilance section of the EFDA and TFDA, respectively. In Tanzania, Ethiopia, Kenya, and Rwanda, the fulltime equivalent staff working in the pharmacovigilance unit were 12 (five at the TDFA headquarters and seven pharmacovigilance focal persons at TFDA zonal offices), ten (six working on clinical trials and four on pharmacovigilance), five (three working on pharmacovigilance and two on PMS) and two, respectively. In Kenya and Tanzania, there were specific annual budgetary allocations for pharmacovigilance activities. In Ethiopia and Rwanda, there were no designated budgets allocated to pharmacovigilance activities, but the budget for such activities was included with other activities managed by the respective directorate/department where the pharmacovigilance unit is placed.

Table 2 Regulations for MAHs in Ethiopia, Kenya, Rwanda and Tanzania

\begin{tabular}{|c|c|c|c|}
\hline Country & $\begin{array}{l}\text { Mandatory by } \\
\text { law/regulations for } \\
\text { MAHs to conduct } \\
\text { PMS activities } \\
\text { and report ADRs/ } \\
\text { medicine safety } \\
\text { issues }\end{array}$ & $\begin{array}{l}\text { Mandatory for } \\
\text { the MAHs to } \\
\text { regularly submit } \\
\text { PSURs or PBR- } \\
\text { ERs }\end{array}$ & $\begin{array}{l}\text { Mandatory for } \\
\text { manufacturers/ } \\
\text { MAHs to have a } \\
\text { QPPV }\end{array}$ \\
\hline Ethiopia & $\checkmark$ & $\checkmark$ & $\mathrm{X}$ \\
\hline Kenya & $\mathrm{X}$ & $\mathrm{X}$ & $\mathrm{X}$ \\
\hline Rwanda & $\checkmark$ & $X$ & $X$ \\
\hline Tanzania & $\checkmark$ & $\checkmark$ & $\checkmark$ \\
\hline
\end{tabular}

$\checkmark$ present, $X$ missing/not available, $A D R$ adverse drug reaction, $M A H$ Marketing Authorization Holder, PBRER Periodic Benefit-Risk Evaluation Report, $P M S$ post-marketing surveillance, $P S U R$ Periodic Safety Update Report, $Q P P V$ Qualified Person Responsible for Pharmacovigilance

Table 1 National pharmacovigilance act, regulation, policy, and guidelines in Ethiopia, Kenya, Rwanda, and Tanzania

\begin{tabular}{|c|c|c|c|c|}
\hline Country & Act & Regulation & Policy & Guideline (s) \\
\hline Ethiopia & Proclamation No. 661/2009 & $\begin{array}{l}\text { Regulation No. 299/2013 } \\
\text { (2013) }\end{array}$ & $\begin{array}{l}\text { The Ethiopian Health Policy } \\
\text { (2000) }\end{array}$ & $\begin{array}{l}\text { Guideline for Adverse Drug } \\
\text { Events Monitoring [Pharma- } \\
\text { covigilance] (2014) }\end{array}$ \\
\hline Kenya & $\begin{array}{l}\text { 1. Pharmacy and Poisons Act, } \\
\text { chapter } 244 \text { (1956) } \\
\text { 2. Health Act (2017) }\end{array}$ & $\begin{array}{l}2018 \text { Pharmacovigilance guide- } \\
\text { lines (draft) }\end{array}$ & Health Sector Policy (2015) & $\begin{array}{l}\text { Pharmacovigilance guidelines } \\
\text { (2009) }\end{array}$ \\
\hline Rwanda & $\begin{array}{l}\text { Law } N^{\circ} 003 / 2018 \text { of } \\
09 / 02 / 2018\end{array}$ & $X$ & $\begin{array}{l}\text { Rwanda Pharmacy Policy } \\
\text { (2016) }\end{array}$ & $\begin{array}{l}\text { Pharmacovigilance guidelines } \\
\text { (2012) }\end{array}$ \\
\hline Tanzania & $\begin{array}{l}\text { Food, Drug and Cosmetics Act } \\
\text { of } 2003\end{array}$ & $\begin{array}{l}\text { 1. Pharmacovigilance regula- } \\
\text { tions (2018) } \\
\text { 2. Regulations on registration } \\
\text { of medicinal products }(2015)\end{array}$ & $\begin{array}{l}\text { The Tanzania National Drug } \\
\text { Policy (1991) }\end{array}$ & $\begin{array}{l}\text { National Guidelines for } \\
\text { Monitoring Medicines Safety } \\
\text { (2018) }\end{array}$ \\
\hline
\end{tabular}

$X$ missing/not available 
In Tanzania, there were established SOPs for receiving and processing ADR reports, reviewing and annotating ADR reports, and development and approval of the ADR bulletin, all reviewed in 2018. The national pharmacovigilance center in Kenya had SOPs for routine management and processing of ICSRs, last reviewed in 2016. Ethiopia had one SOP for receiving and processing ICSRs. In Rwanda, SOPs for routine operation of the pharmacovigilance center and its management and processing of reports of suspected ADRs were being developed for adoption.

A national medicine safety advisory committee provides technical advice on the safety of medicines to the regulatory authority. In Tanzania, there was a technical committee for pharmacovigilance and adverse events following immunization (AEFIs), supporting the national pharmacovigilance program. In Ethiopia and Kenya, the committees that supported the national pharmacovigilance programs on pharmacovigilance issues were the causality assessment of AEFI committee and the clinical trials committee, respectively. Kenya has plans to establish a separate Kenya Pharmacovigilance Risk Assessment and Advisory Committee (PRAAC), taking over the responsibilities for medicine safety issues from the previous committee. Ethiopia has transformed the AEFIs committee to a general safety advisory committee. Rwanda has not yet established a national medicine safety advisory committee.

The latest issue of the National List of Essential Medicines in Tanzania, Kenya, Ethiopia, and Rwanda was published in 2017, 2016, 2015, and 2015, respectively. All four countries had a process for development of the National List of Essential Medicines; the review was managed by the respective ministries responsible for health. In Kenya, Tanzania, and Ethiopia, the NMRAs were represented on the National List of Essential Medicines committee, and their role was to provide information on safety data for consideration; these data are rarely based on local experience, because of the low level of ICSRs in the respective countries. In Rwanda, a multi-stakeholder working group assigned by the ministry of health is tasked with this process, but the pharmacovigilance division is not part of the working group.
The submission of ICSRs from healthcare facilities was very low. In the last calendar year (2017/2018), the proportion of health facilities that reported suspected ICSRs to national pharmacovigilance systems in Ethiopia, Kenya, and Tanzania was $\leq 1 \%$ of the total number of health facilities per country. There was no pre-service pharmacovigilance training for healthcare professional students in Rwanda, Kenya, and Tanzania (Table 3). In 2013, the national pharmacovigilance center in Ethiopia in collaboration with universities in the country developed a harmonized training curriculum in pharmacovigilance for undergraduate courses in medical, pharmacy, and nursing schools. This was supported by the Ministry of Education, but not yet adopted or implemented. The national pharmacovigilance centers in Ethiopia, Kenya, and Tanzania provide in-service pharmacovigilance training to healthcare professionals:

- In Ethiopia, 2-3 days training on ADRs and separate training for AEFIs (for 20-40 attendees per session) was given in the last calendar year (2017/2018). A total of 1300 health professionals and decision-makers were trained.

- In Kenya, the national pharmacovigilance system provides three types of training: 5-day, 3-day, and 1-day training courses. The 1-day training course was updated in 2018; the other two training courses were last revised in 2012. In the last calendar year, 384 health professionals were trained throughout the country. In the last calendar year, the national pharmacovigilance system in Kenya participated in 12 training sessions; six were conducted by the pharmacovigilance system, and the other six were in collaboration with partners.

- In Tanzania, they used a 5-day training-of-trainers (ToTs) model, and nine such training sessions were conducted in the last calendar year. Additionally, 1253 individuals were reached through 13 sensitization activities in the last calendar year.

Table 3 National systems, structures, and stakeholder coordination in Ethiopia, Kenya, Rwanda, and Tanzania

\begin{tabular}{|c|c|c|c|c|c|c|c|c|}
\hline Country & $\begin{array}{l}\text { Defined annual budget } \\
\text { for pharmacovigilance }\end{array}$ & $\begin{array}{l}\text { Existence of a source } \\
\text { of data on consumption } \\
\text { and/or prescription of } \\
\text { medicines }\end{array}$ & $\begin{array}{l}\text { Pre- } \\
\text { service } \\
\text { training }\end{array}$ & $\begin{array}{l}\text { In- } \\
\text { service } \\
\text { training }\end{array}$ & $\begin{array}{l}\text { Web- } \\
\text { based } \\
\text { training }\end{array}$ & $\begin{array}{l}\text { Communication plan } \\
\text { to disseminate pharma- } \\
\text { covigilance information }\end{array}$ & $\begin{array}{l}\text { Toll- } \\
\text { free } \\
\text { number }\end{array}$ & Website \\
\hline Ethiopia & $X$ & $X$ & $\checkmark$ & $\checkmark$ & $X$ & $\checkmark$ & $\checkmark$ & $\checkmark$ \\
\hline Kenya & $\checkmark$ & $\mathrm{X}$ & $\mathrm{X}$ & $\checkmark$ & $X$ & $\vee^{\mathrm{a}}$ & $\mathrm{X}$ & $\checkmark$ \\
\hline Rwanda & $X$ & $X$ & $X$ & $X$ & $X$ & $\mathrm{X}$ & $X$ & $X$ \\
\hline Tanzania & $\checkmark$ & $X$ & $X$ & $\checkmark$ & $X$ & $\checkmark$ & $\checkmark$ & $\checkmark$ \\
\hline
\end{tabular}

$\checkmark$ present, $X$ missing/not available, NMRA National Medicines Regulatory Authority, $P P B$ Pharmacy and Poisons Board

${ }^{a}$ No specific plan for pharmacovigilance; communication plan available for the NMRA (PPB), but not specific to pharmacovigilance 
There was no web-based training/continuing education for professional development facilities in any of the four countries.

None of the national pharmacovigilance systems had a source for statistics on the volume of sales, consumption, and/or prescription of medicines (Table 3). Ethiopia and Tanzania have a communication plan for pharmacovigilance. In Kenya, there is a general PPB communication plan, but it is not specific to pharmacovigilance. In Rwanda, the newly established Rwanda FDA did not have a communication plan for dissemination of safety information. The main dissemination mechanisms for pharmacovigilance information are drug safety bulletins/newsletters and websites in Ethiopia, Kenya, and Tanzania. In Ethiopia and Tanzania, the bulletin/newsletter is scheduled to be published four and two times a year, respectively, but during the last 12 months, only one issue was produced in each country. In Kenya, PPB issued an annual pharmacovigilance newsletter, and a quarterly summary report is available on the PPB website. All the national pharmacovigilance centers, except for the newly established Rwanda FDA had websites. The national pharmacovigilance centers in Ethiopia and Tanzania had a toll-free telephone number for use by the public for pharmacovigilance information. The public can make calls to the national pharmacovigilance center in Kenya, but the line is not toll-free. Reporters may also send SMS messages and will then be called back. The Rwanda Ministry of Health has a toll-free telephone number that is open to the public for asking questions, not specific to pharmacovigilance issues. Other channels used for dissemination of pharmacovigilance information are group emailing and communication applications like WhatsApp (not in Ethiopia, due to IT policy), radio, and television.

\subsection{Signal Generation and Data Management}

All the national pharmacovigilance centers had a national database for managing data, although the central database in Rwanda was not in use (Table 4). This is because at the time of the assessment, the internal human resource competence for operating the VigiFlow case management system was lost and no replacement had been recruited and/or trained. Infrastructure necessary for continuing the use of VigiFlow as the national ICSR management system is in place at the Rwanda FDA in terms of availability of computers and access to the internet.

All the four pharmacovigilance centers have AE reporting forms, mainly for healthcare professionals. Only Tanzania has one for consumers/patients, which is in the local language, Swahili. In Kenya and Tanzania, there is an electronic AE reporting system. The specific medicine-related problems that can be reported in the standard AE reporting forms in each of the four countries are shown in Table 5. In Kenya, Rwanda, and Tanzania, a separate reporting form was used for product quality issues. In Ethiopia and Kenya, there are separate reporting forms for AEFIs.

In Kenya and Rwanda, there was no reporting mechanism for problems associated with medical devices and diagnostics. In Tanzania, there was a separate form for medication errors or problems associated with medical devices and diagnostics. The national pharmacovigilance centers in Kenya, Tanzania, and Ethiopia have developed SOPs for data management and signal analysis. In Rwanda, there was no process in place for collection, recording, and analysis of ADR reports.

\subsection{Risk Assessment and Evaluation}

In Ethiopia, Rwanda, and Tanzania the number of registered products with a pharmacovigilance plan and/or a risk management strategy from MAHs was not recorded. In Kenya, Periodic Update Safety Reports (PUSRs) were submitted for all approximately 10,000 registered products, including innovator and generics. The national pharmacovigilance centers in Tanzania, Ethiopia, and Kenya have conducted three, one, and one cohort event monitoring (CEM) study, respectively, in the last 3 years (36 months). The CEM study initiated by the pharmacovigilance center in Ethiopia was later outsourced to another institute with better resources.

Table 4 National signal generation and data management system in Ethiopia, Kenya, Rwanda, and Tanzania

\begin{tabular}{llllll}
\hline Country & $\begin{array}{l}\text { Existence of a national } \\
\text { database for pharma- } \\
\text { covigilance information }\end{array}$ & $\begin{array}{l}\text { Existence of standard } \\
\text { adverse event reporting } \\
\text { form }\end{array}$ & $\begin{array}{l}\text { Existence of standard } \\
\text { adverse event reporting } \\
\text { form for the public }\end{array}$ & $\begin{array}{l}\text { Existence of electronic } \\
\text { adverse event reporting } \\
\text { system }\end{array}$ & $\begin{array}{l}\text { Process for collection, } \\
\text { recording, and analysis of } \\
\text { ADR reports }\end{array}$ \\
\hline Ethiopia & $\checkmark$ & $\checkmark$ & $\mathrm{X}$ & $\mathrm{X}$ & $\checkmark$ \\
Kenya & $\checkmark$ & $\checkmark$ & $\mathrm{X}$ & $\checkmark$ & $\checkmark$ \\
Rwanda & $\checkmark$ & $\mathrm{X}$ & $\mathrm{X}$ & $\checkmark$ & $\mathrm{X}$ \\
Tanzania & $\checkmark$ & $\checkmark$ & $\checkmark$ & $\checkmark$ & \\
\hline
\end{tabular}

$\checkmark$ present, $X$ missing/not available, $A D R$ adverse drug reaction

${ }^{\text {a}}$ Database was not in use 
No active pharmacovigilance studies have been carried out by the national pharmacovigilance center in Rwanda.

The national pharmacovigilance centers in Kenya, Tanzania, Ethiopia, and Rwanda have submitted 11,373, 1899, 1331, and 30 Individual Case Safety Reports (ICSRs) to VigiBase since joining the WHO PIDM to December 2018 (Table 6).

The rates of suspected ICSRs received during 2017/2018 in Kenya, Ethiopia, and Tanzania were 35, 6.7, and 4.1 per million, respectively, based on an estimated population of "Worldometers" in 2017 (Fig. 1) [21]. In Tanzania, all the suspected ICSRs received were reports of suspected ADRs. The Rwanda FDA received no ICSRs in 2017/2018. Since 2014, the national pharmacovigilance center, initially under the Pharmacy Task Force unit of the Rwanda Ministry of Health, had only received five ICSRs.

In Ethiopia, 72\% $(n=504)$ of ICSRs received referred to suspected ADRs, of which $47 \%(n=235)$ came from the tuberculosis program (see Fig. 2). In Kenya, 85\% ( $n=1468)$ and $8 \%(n=132)$ of all ICSR reports received were on ADRs and AEFIs, respectively; a majority, $76 \%(n=1320)$, of the ICSRs that the national pharmacovigilance center received emanated from the national HIV/AIDS program. In Ethiopia and Kenya, 26\% $(n=181)$ and $8 \%(n=137)$ of the ICSRs received referred to product quality issues, respectively. In Tanzania, 90\% of the ICSRs were on suspected ADRs; the remaining $10 \%$ were on medical devices and diagnostics.

None of the four countries received ICSRs from MAHs. The national pharmacovigilance systems in Kenya and Ethiopia received 142 and 118 reports from MAHs, respectively. In Kenya, most MAH reports used the Council for International Organizations of Medical Sciences (CIOMS) summary, and hence, the reports were not included in the PPB database. In Ethiopia, the reports from MAHs were in the form of PSURs.

In Tanzania, during the last calendar year, 97\% $(n=228)$ of ICSRs were subjected to causality assessment. In Ethiopia and Kenya, in the last calendar year, the proportions of ICSRs that were subjected to causality assessment were $2.0 \%(n=14)$ and $5.5 \%(n=96)$, respectively. The VigiGrade completeness scores (a measure of the amount of
Table 6 Total ICSRs submitted to the WHO PIDM since year of entry to 2018

\begin{tabular}{llc}
\hline Country & $\begin{array}{l}\text { Joined WHO } \\
\text { PIDM (year) }\end{array}$ & $\begin{array}{l}\text { Total number of ICSRs submitted to } \\
\text { VigiBase since joining PIDM to 2018 }\end{array}$ \\
\hline Ethiopia & 2008 & 1331 \\
Kenya & 2010 & 11,373 \\
Rwanda & 2013 & 30 \\
Tanzania & 1993 & 1899 \\
\hline
\end{tabular}

ICSR Individual Case Safety Report, PIDM Programme for International Drug Monitoring, WHO World Health Organization

information on ICSRs) of quarterly reports submitted to VigiBase in 2017/2018 for Ethiopia, Kenya, and Tanzania were $0.87,0.72$, and 0.57 , respectively, out of a maximum score of 1.0 [22]. In Rwanda and Ethiopia, none of the health facilities reported ten or more ICSRs. In Kenya and Tanzania, the number of health facilities that reported ten or more ICSRs was 15 and 3, respectively. The number of health facilities in Ethiopia, Kenya, Rwanda, and Tanzania was 20,298 (2015), $10,864,7072$, and 1140 , respectively.

\subsection{Risk Management and Communication}

In the last calendar year, pharmacovigilance activities in Ethiopia, Kenya, and Tanzania have resulted in four product withdrawals, 13 product recalls (voluntary and regulatory), and two withdrawals, respectively. Most of the recalls were related to poor quality. In the last 8 years, 31 regulatory actions were documented relating to pharmacovigilance activities in Ethiopia. In most instances, actions were based on the poor quality of the product, identified through reports of adverse reactions. In Kenya, 30 signals relating to substandard quality of medicines were detected, and one medicine safety signal was identified during the past year. In Tanzania, on an average, five safety signals have been identified per year during the last 5 years, and regulatory actions were taken. The average time from first identification of a suspected problem until regulatory action varies between the four countries. In Ethiopia, it took 2-3 months, depending on the nature of the investigation needed. In

Table 5 Specific medicine-related problems to be reported using standard reporting forms or a separate form $\left({ }^{a}\right)$ in Ethiopia, Kenya, Rwanda, and Tanzania

\begin{tabular}{lllllll}
\hline Country & $\begin{array}{l}\text { Adverse events/ } \\
\text { reactions }\end{array}$ & $\begin{array}{l}\text { Therapeutic inef- } \\
\text { fectiveness }\end{array}$ & $\begin{array}{l}\text { Medication } \\
\text { errors }\end{array}$ & $\begin{array}{l}\text { Medical devices and } \\
\text { diagnostics }\end{array}$ & $\begin{array}{l}\text { Misuse, abuse, and/or } \\
\text { dependence }\end{array}$ & $\begin{array}{l}\text { Poor quality } \\
\text { AEFIs }\end{array}$ \\
\hline Ethiopia & $\checkmark$ & $\checkmark$ & $\checkmark$ & $\checkmark$ & $\checkmark$ & a \\
Kenya & $\checkmark$ & $\checkmark$ & $\checkmark$ & X & $\checkmark$ & a \\
Rwanda & $\checkmark$ & $\checkmark$ & X & X & a & a \\
Tanzania & $\checkmark$ & $\checkmark$ & $\checkmark$ & $\checkmark$ & $\checkmark$ \\
\hline
\end{tabular}

$\checkmark$ present in the standard reporting form, ${ }^{\text {a }}$ present in a separate form, $X$ missing/not available, $A E F I$ adverse events following immunization 
Fig. 1 Number of spontaneous ICSRs per million in 2017/2018 in Ethiopia, Kenya, and Tanzania. ICSR Individual Case Safety Report
Fig. 2 Percentage of ICSRs received in the different subindicators in Ethiopia, Kenya, and Tanzania in 2017/2018. $A D R$ adverse drug reaction, $A E F I$ adverse events following immunization
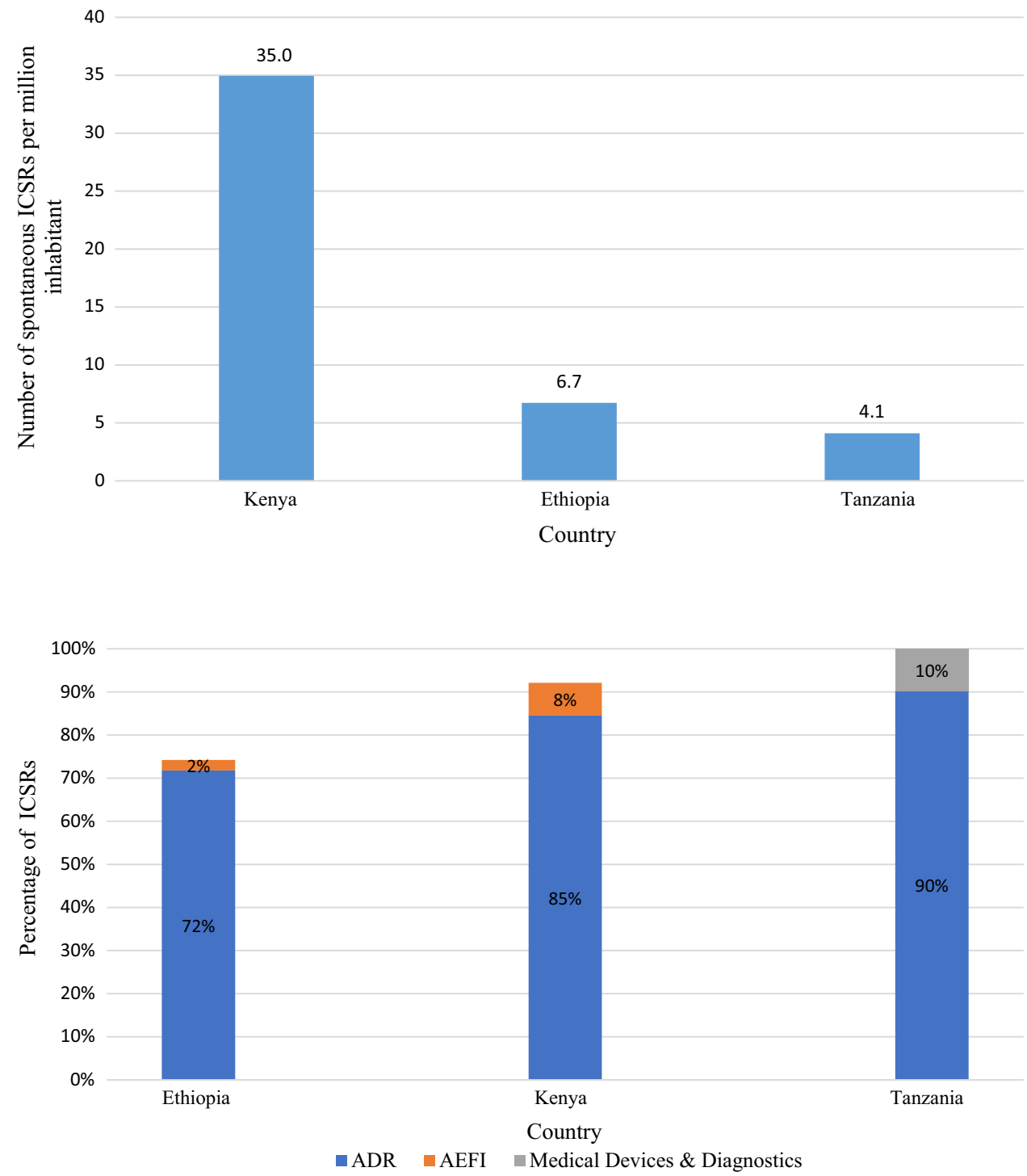

Kenya, the average time was between 7 days and 3 months, depending on the nature of the case. For Tanzania, it took anywhere between days to weeks, depending on the severity. The Rwanda FDA was established in 2018, and its Division of Pharmacovigilance and Safety Monitoring had new staff. No ICSR reports were received during the last calendar year, and therefore no activities of signal detection and analysis took place.

Tanzania was the only country that recorded requests for information about medicine safety from professionals or the public. In the last year, the national pharmacovigilance center received 36 requests, and all were addressed. In Ethiopia, requests for information about medicines were managed by another department (the Health Regulatory Information Centre). No statistical records were kept at the pharmacovigilance center regarding the number or nature of such requests. In Kenya, information about medicine safety was received and addressed, but the number of requests was not recorded; hence, it is unknown.

The national pharmacovigilance systems in Kenya and Tanzania act upon medicine safety issues reported from abroad. In Kenya, five medicine safety issues reported from abroad were acted upon in the last year. The national pharmacovigilance system in Ethiopia has not initiated any regulatory action based on information about safety issues received from the WHO or individual countries. The newly established Rwanda FDA has no activities to report relating to safety communication with the pharmacovigilance stakeholders, and no relevant regulatory decisions have been taken, neither based on domestic nor data from abroad.

In Ethiopia, the national pharmacovigilance toll-free number was regularly promoted at 7.00 am on national morning radio broadcasting. There was no information provided on the number/type of awareness/sensitization activities related to medicine safety that have been targeted 
towards the public. In Kenya, public educational activities have been carried out via newspaper articles, television, or roadshows. In Tanzania, the national pharmacovigilance system engaged in public education related to medicines and their safety, such as through broadcast media (television and radio) on about five channels.

\section{Discussion}

This study assessed and compared the performance of national pharmacovigilance systems in Ethiopia, Kenya, Rwanda, and Tanzania hosted at the respective NMRAs to provide an overview of the current status and performance of the pharmacovigilance systems. In all four participating East African countries, the NMRAs have the policy and legal frameworks defined by law and regulation to conduct pharmacovigilance activities in their respective countries. The existence of laws and regulations supporting pharmacovigilance activities indicates that the countries are committed to maintaining and improving the safe use and quality of medicines made available in the pharmaceutical supply systems [8].

The involvement of MAHs in the national pharmacovigilance systems in the four countries is inadequate. In Tanzania, it is mandatory for MAHs to submit their PSURs and PBRERs every 6 months, but no such results had been presented to the authority. In order to improve their compliance, in Ethiopia, Kenya, and Rwanda, the requirements for MAHs to contribute to the pharmacovigilance system need to be strengthened to the level of regulation rather than being based on guidelines. The compliance of MAHs should be well-matched with the ability of pharmacovigilance staff to comprehend and critically review documents from MAHs such as PSURs and PBRERs. Therefore, the national staff at the NMRAs need to be trained to process and analyze documents requested from MAHs.

Overall, the regulatory support for pharmacovigilance in Ethiopia, Kenya, Rwanda, and Tanzania is in line with current international standards, and all the regulatory pharmacovigilance centers, except the newly established Rwanda FDA, had the systems and structures to conduct pharmacovigilance activity. Recently, the TFDA, now referred to as TMDA, reached WHO GBT performance maturity level 3, meaning that the institution is stable and well-functioning, with an integrated regulatory pharmacovigilance system [23]. However, the WHO assessment only took into account the structures and functions of the regulatory authority and did not reflect the low number of reports received by the national pharmacovigilance center due to a lack of engagement from relevant stakeholders such as healthcare providers/facilities, Public Health Programmes (PHPs), MAHs, and civil society/consumers. The national pharmacovigilance system in Rwanda was previously hosted by the Rwanda Ministry of Health under the directorate of pharmaceutical services. At present, it is hosted by the Rwanda FDA, which was established in 2018. There have been very few ICSRs (five reports) submitted to the agency since 2014. In Ethiopia, Kenya, and Tanzania, the rates of spontaneous ICSRs were $6.7,35.0$, and 4.1 per million inhabitants, respectively; these numbers are very low compared to the rest of the world. In 2015, the proportion of ICSRs from Africa was $0.88 \%$ of the total reports received in VigiBase (the WHO global ICSR database maintained by UMC); the cumulative number of ICSRs from Africa was 103,499 out of the global total of $11,824,804[24,25]$. In 2015 , a study reported the ICSRs of African countries; in Ethiopia, Kenya, the Republic of Tanzania (mainland and Zanzibar), and Rwanda, the rates of ICSRs per million inhabitants were 1.28, 39.07, 1.68 , and 1.21 , respectively [24]. In 2019, the proportion of reports from Africa was $0.9 \%$, indicating very low reporting rates among African countries. A study highlighted that the number of reports received from Africa is not sufficient to identify significant drug-related issues [25]. The study encouraged the African countries to report more because the safety information sourced from the WHO global database might not always be relevant for local settings in individual countries [25]. This is important because data from countries with similar demographics, genetic background, nutritional status and background, and co-morbidities should be in one data repository, such as the WHO VigiBase database so that analysis of the pooled data can be done to provide relevant solutions [25].

Another similar challenge that all the national pharmacovigilance systems hosted at the respective NMRAs have is limited financial and human resources. While the national pharmacovigilance systems in Kenya and Tanzania have a specific budget for pharmacovigilance activities, Ethiopia and Rwanda do not have such a budget. However, even in the countries with allocated budgets for pharmacovigilance activities, these budgets need to be improved so that they are well-matched with the resource requirements for enforcement of the respective pharmacovigilance regulations and guidelines. Building and maintaining pharmacovigilance systems is a complex operation requiring amongst other things a sustainable budget [3]. During the study period, all the four countries were in the process of implementing new regulations and guidelines. It is therefore important that in these guidelines, issues related to human resource and budgetary allocation for pharmacovigilance activities be emphasized for successful implementation of these instruments.

Only the national pharmacovigilance system in Ethiopia out of the four countries had pre-service pharmacovigilance training, although even in Ethiopia, the impact of the pre-service pharmacovigilance training is unknown. Preservice pharmacovigilance education is a sustainable and 
cost-effective intervention that strengthens health systems $[1,8]$. The pre-service pharmacovigilance training in all four countries needs to be strengthened across different healthcare professional training programs. Trainees for pre-service pharmacovigilance training are future healthcare professionals, and it is important that they understand their role in the safety monitoring and safe use of medicines. Lack of knowledge of the reporting processes of suspected AEs is the main cause for underreporting [26, 27]. Pre-service pharmacovigilance training across different healthcare professional programs including the ADR reporting process may promote reporting [9]. The inclusion of higher learning institutions that provide training for healthcare professionals as stakeholders in the national pharmacovigilance system is crucial for sustainability of the programs.

In Ethiopia and Kenya, a large proportion of the ICSRs emanated from a public health program (tuberculosis in Ethiopia 47\%, HIV/AIDS in Kenya 76\%). This fact indicates the importance of creating partnerships with PHPs for careful safety surveillance of the high number of patients that are being treated. The very low number of ICSRs received may not reflect all medicine-related harms happening in the healthcare system. Another indication of this fact is that the majority of restrictive regulatory actions that were taken in the four countries were mainly due to quality-related concerns. Clinical manifestations of medicine-related harm are common in all healthcare systems [28], and a high proportion of them are normally preventable, such as medication errors, but they are currently not being picked up by the pharmacovigilance systems in the four studied countries.

Stakeholder coordination needs to be strengthened to increase ICSR reporting. Ethiopia, Kenya, and Rwanda should consider promoting direct patient reporting. In Rwanda, the national pharmacovigilance system should also consider having electronic reporting systems and mobile phone reporting applications; this may increase the number of reports.

Although all NMRAs had national data on drug importation, none of the national pharmacovigilance systems had a source of data on consumption and prescription of medicines; hence, the national pharmacovigilance systems do not have information on the level of drug utilization in the respective countries. Drug utilization data at the population level are essential to weigh the potential risk of drugrelated harm and assess the public health impact of ADRs. The national pharmacovigilance systems should establish a mechanism to capture medicine utilization data (which form the denominator for calculating the reporting rate), weigh the drug risk at the population level, prioritize safety signals, and follow-up the impact of regulatory actions.

At present, there are many ongoing initiatives to strengthen pharmacovigilance systems and ensure medicine safety in Africa. For instance, the Rwanda FDA has just launched its pharmacovigilance guidelines, and the EFDA has recently introduced an electronic $\mathrm{AE}$ reporting system for healthcare professionals. Hence, there is a need for continuous assessment of the systems to identify the real gaps that need to be addressed. The findings of this study have provided a comprehensive understanding of the national pharmacovigilance systems in East Africa. However, as a result of the many ongoing initiatives, findings for some of the indicators may have changed since the assessment.

Overall, most of the information captured in this study was verified using sources of documentation such as legal documents, guidelines, training materials, terms of reference for safety advisory committees, and SOPs for the management and routine operation of the pharmacovigilance systems. Additionally, a selection of MAHs, PHPs, and health facilities were assessed using the EAC Harmonized Pharmacovigilance Indicators tool to gather more information on the functioning of the pharmacovigilance systems in all the four countries. However, some personal knowledge, experience, and opinions of the regulators were not possible to verify from other sources.

\section{Conclusion}

In general, the national pharmacovigilance systems in all four countries in East Africa are supported by legal instruments and guidelines. New regulations or guidelines aiming at convergence with international standards in pharmacovigilance are currently being introduced in all countries. Despite having legal support and pharmacovigilance systems and structures, limited stakeholder involvement and engagement in the pharmacovigilance systems manifested in very low reporting rates. In all the four countries, procedures for data collection, management, signal analysis, and decision making are in place or are being introduced. However, at the time of the assessment, the pharmacovigilance systems did not have the full capacity to systematically identify new problems related to pharmaceutical products happening in healthcare delivery systems.

There is a need to design and/or implement interventions targeting all relevant stakeholders, including public health programs, healthcare facilities and professionals, academic institutions, and consumers/patients, to build an effective national pharmacovigilance system. The pharmacovigilance systems and structures in the respective countries have some similarities. However, they do have some differences, and therefore, interventions need to be designed to address local needs in the individual countries.

Acknowledgements Open access funding provided by Karolinska Institute. We thank the National Medicines Regulatory Authorities (NMRAs) in Ethiopia, Kenya, Rwanda, and Tanzania, namely the 
Ethiopian Food and Drug Authority, the Pharmacy and Poisons Board, Kenya, the Rwanda Food and Drugs Authority, and the Tanzania Medicines and Medical Devices Authority, respectively, for their cooperation and assistance during data collection.

\section{Compliance with Ethical Standards}

Conflict of interest Abbie Barry, Sten Olsson, Omary Minzi, Emile Bienvenu, Eyasu Makonnen, Appolinary Kamuhabwa, Margaret Oluka, Anastasia Guantai, Ulf Bergman, Eugène van Puijenbroek, Parthasarathi Gurumurthy, and Eleni Aklillu have no conflict of interest.

Funding This study was conducted as part of the Pharmacovigilance infrastructure and post-marketing surveillance system capacity building for regional medicine regulatory harmonization in East Africa (PROFORMA) project funded by the European \& Developing Countries Clinical Trials Partnership (EDCTP) 2 program supported by the European Union (Grant number CSA2016S-1618) and the Swedish International Development Cooperation Agency (Sida).

Data sharing All data generated or analyzed during this study are included in this published article.

Open Access This article is licensed under a Creative Commons Attribution-NonCommercial 4.0 International License, which permits any non-commercial use, sharing, adaptation, distribution and reproduction in any medium or format, as long as you give appropriate credit to the original author(s) and the source, provide a link to the Creative Commons licence, and indicate if changes were made. The images or other third party material in this article are included in the article's Creative Commons licence, unless indicated otherwise in a credit line to the material. If material is not included in the article's Creative Commons licence and your intended use is not permitted by statutory regulation or exceeds the permitted use, you will need to obtain permission directly from the copyright holder.To view a copy of this licence, visit http://creativecommons.org/licenses/by-nc/4.0/.

\section{References}

1. Systems for Improved Access to Pharmaceuticals and Services (SIAPS) Program. Comparative analysis of pharmacovigilance systems in five Asian countries. Submitted to the US Agency for International Development by the Systems for improved access to Pharmaceuticals and Services (SIAPS) Program. Arlington, VA: Management Sciences for Health; 2013.

2. Ndomondo-Sigonda M, Miot J, Naidoo S, Dodoo A, Kaale E. Medicines regulation in Africa: current state and opportunities. Pharm Med. 2017;31(6):383-97.

3. Olsson S, Pal SN, Dodoo A. Pharmacovigilance in resource-limited countries. Expert Rev Clin Pharmacol. 2015;8(4):449-60.

4. Choi LH, Nwokike J, Boni A, Lee D. Comprehensive assessment of pharmacovigilance systems and their performance in Sub-Saharan Africa. In: 11th international conference of drug regulatory authorities presented. China; 2012. p. 2012.

5. Isah AO, Pal SN, Olsson S, Dodoo A, Bencheikh RS. Specific features of medicines safety and pharmacovigilance in Africa. Ther Adv Drug Saf. 2012;3(1):25-34.

6. World Health Organisation. Essential medicines and health products: improving the quality of medical products for universal access. WHO. 2018. https://www.who.int/medicines/regulation /fact-figures-qual-med/en/. Accessed 03 Dec 2018.
7. World Health Organisation. First African Medicines Regulatory Authorities Conference. WHO. Addis Ababa; 2005. http://apps. who.int/medicinedocs/en/m/abstract/Js17809en/. Accessed 03 Dec 2018.

8. Strengthening Pharmaceutical Systems (SPS). Safety of medicines in Sub-Saharan Africa: assessment of pharmacovigilance systems and their performance. Submitted to the US Agency for International Development by the Strengthening Pharmaceutical Systems (SPS) Program. Arlington, VA: Management Sciences for Health; 2011.

9. Lopez-gonzalez E, Herdeiro MT, Figueiras A. Determinants of under-reporting of adverse drug reactions a systematic review. Drug Saf. 2009;32(1):19-31.

10. Mekonnen AB, Alhawassi TM, McLachlan AJ, Brien JE. Adverse drug events and medication errors in African hospitals: a systematic review. Drugs Real World Outcomes. 2018;5(1):1-24.

11. Renschler JP, Walters KM, Newton PN, Laxminarayan R. Estimated under-five deaths associated with poor-quality antimalarials in Sub-Saharan Africa. Am J Trop Med Hyg. 2015;92(Suppl 6):119-26.

12. Uppsala Monitoring Centre. Members of the WHO Programme for International Drug Monitoring. 2018. https://www.who-umc. org/global-pharmacovigilance/members/who-programme-membe rs/. Accessed 02 Nov 2018.

13. World Health Organization. Joining the WHO Programme for International Drug Monitoring. https://www.who.int/medicines/ areas/quality_safety/safety_efficacy/JoiningWHOProgrammef orInternationaDrugMonitoring.pdf. Accessed 04 Jun 2018.

14. Patra SK, Muchie M. Safeguarding health and well-being of people: how clinical trials in Africa set for sustainable development goals? Asian Biotechnol Dev Rev. 2017;19(3):3-23.

15. World Health Organization. Guidelines for good clinical practice (GCP) for trials on pharmaceutical products. 1995. https://apps. who.int/medicinedocs/pdf/whozip13e/whozip13e.pdf. Accessed 01 Mar 2018.

16. Autran B, Asturias EJ, Evans S, Hartigan-Go K, Hussey G, John TJ, et al. Global safety of vaccines: strengthening systems for monitoring, management and the role of GACVS. Expert Rev Vaccines. 2009;8(6):705-16.

17. Pharmacovigilance infrastructure and post-marketing surveillance system capacity building for regional medicine regulatory harmonization in East Africa (PROFORMA) [Internet]. https://profo rma.ki.se/. Accessed 02 May 2019.

18. World Health Organization. WHO pharmacovigilance indicators-a practical manual for the assessment of pharmacovigilance systems. 2015. https://www.who.int/medicines/areas/quality_safet y/safety_efficacy/EMP_PV_Indicators_web_ready_v2.pdf. Accessed 24 May 2018.

19. Strengthening Pharmaceutical Systems (SPS) Program S. Indicator-based pharmacovigilance assessment tool: manual for conducting assessments in developing countries. Arlington: Management Sciences for Health; 2009.

20. World Health Organization. WHO global benchmarking tool (GBT) for evaluation of national regulatory systems. https://www. who.int/medicines/regulation/03_GBT_VL_RevVI.pdf?ua=1. Accessed 24 May 2018.

21. Worldometers. Population [Internet]. Worldometers. https://www. worldometers.info/population/. Accessed 10 Dec 2018.

22. Bergvall T, Niklas Norén G, Lindquist M. VigiGrade: a tool to identify well-documented individual case reports and highlight systematic data quality issues. Drug Saf. 2014;37(1):65-77.

23. World Health Organization-Regional Office for Africa. Tanzania Food and Drug Authority becomes the first to reach level 3 of the WHO benchmarking programme. WHO-Regional Office for Africa. 2018. https://www.afro.who.int/news/tanza 
nia-food-and-drug-authority-becomes-first-reach-level-3-whobenchmarking-programme. Accessed 18 May 2019.

24. Ampadu HH, Hoekman J, de Bruin LM, Pal SN, Olsson S, Sartori $\mathrm{D}$, et al. Adverse drug reaction reporting in Africa and a comparison of Individual Case Safety Report characteristics between Africa and the rest of the world: analyses of spontaneous reports. Drug Saf. 2016;39(4):335-45.

25. Olsson S, Pal SN, Stergachis A, Couper M. Pharmacovigilance activities in 55 low- and middle-income countries a questionnairebased analysis. Drug Saf. 2010;33(8):689-703.

26. Mirbaha F, Shalviri G, Yazdizadeh B, Gholami K, Majdzadeh R. Perceived barriers to reporting adverse drug events in hospitals: a qualitative study using theoretical domains framework approach. Implement Sci. 2015;10(1):1-10.

27. Qassim S, Metwaly Z, Shamsain M, Al-Harir Y. Spontaneous reporting of adverse drug reactions in UAE: obstacles and motivation among community pharmacists. Int J Pharm Sci Res. 2017;5:510.

28. World Health Organization. 10 facts on patient safety. WHO. https ://www.who.int/features/factfiles/patient_safety/en/. Accessed 31 May 2019.

\section{Affiliations}

\section{Abbie Barry $^{1}$ (D) Sten Olsson ${ }^{1}$ (D) Omary Minzi ${ }^{2} \cdot$ Emile Bienvenu $^{3}$ - Eyasu Makonnen ${ }^{4,8}$. Appolinary Kamuhabwa ${ }^{2}$ - Margaret Oluka ${ }^{5}$. Anastasia Guantai ${ }^{5}$ - Ulf Bergman ${ }^{1}$ - Eugène van Puijenbroek ${ }^{6}$. Parthasarathi Gurumurthy ${ }^{7}$ (D) . Eleni Aklillu ${ }^{1}$ (D)}

1 Division of Clinical Pharmacology, Department of Laboratory Medicine, Karolinska Institutet, Karolinska University Hospital Huddinge, 14186 Stockholm, Sweden

2 Department of Clinical Pharmacy and Pharmacology, School of Pharmacy, Muhimbili University of Health and Allied Sciences, P. O. BOX 65013, Dar es Salaam, Tanzania

3 School of Medicine and Pharmacy, University of Rwanda, P. O. BOX 4285, Kigali, Rwanda

4 College of Health Sciences, Addis Ababa University, Addis Ababa, Ethiopia
5 Department of Pharmacology and Pharmacognosy, School of Pharmacy, University of Nairobi, P. O BOX 19676-00202, Nairobi, Kenya

6 Pharmacovigilance Centre Lareb, 's-Hertogenbosch, The Netherlands

7 Pharmacovigilance and Clinical Trials, Botswana Medicines Regulatory Authority, Gaborone, Botswana

8 Center for Innovative Drug Development and Therapeutic Trials for Africa (CDT Africa), College of Health Sciences, Addis Ababa University, Addis Ababa, Ethiopia 